\title{
E-Sucupira: o Coronelismo Eletrônico como herança do Coronelismo nas comunicações brasileiras
}

\author{
Suzy dos Santos 1 \\ Universidade de Brasília \\ suzysantos@gmail.com
}

\begin{abstract}
Resumo: $E$ possível adaptar o conceito coronelismo ao campo da comunicação a partir do adendo "eletrônico"? Podemos dizer que a propriedade de meios de comunicação é similar ao que foi a propriedade da terra na Primeira República? Seriam o "radinho de pilha" e a TV aberta as novas enxadas? Se estamos falando de coronelismo eletrônico, podemos também falar de clientelismo, mandonismo, patrimonialismo ou municipalismo eletrônicos? A consideração de que há um limite histórico a datar o coronelismo se reflete no ambiente das comunicações? Á luz da literatura historiográfica relativa ao coronelismo, tentamos resgatar um conjunto de enunciados deste sistema e defender sua pertinência enquanto herança conceitual conveniente à proposição de uma categoria analítica para o modelo brasileiro de comunicações. Para isso, será necessário: contextualizar o coronelismo e sua adoção nas análises comunicacionais, delimitar algumas fronteiras, apontar algumas imprecisões e inconsistências corriqueiras, e, por fim, especificar nossa proposta de cinco enunciados herdados do coronelismo para constituir o coronelismo eletrônico.
\end{abstract}

Palavras-chave: Coronelismo eletrônico, televisão, radiodifusão, mercado brasileiro de comunicações.

1 Pesquisadora Associada Adjunta no Laboratório de Políticas de Comunicação do Programa de Pós-Graduação em Comunicação da Universidade de Brasília, com bolsa recém-doutora da Fundação Ford e apoio à pesquisa do CNPq. suzysantos@gmail.com 
Resumen: Es posible transponer el concepto de coronelismo para el campo de la comunicación, agregando el adjetivo "electrónico"? Podemos afirmar que la propiedad de los medios de comunicación es similar a lo que fué la propiedad de la tierra durante la Primera República? La radio portatil y la TV abierta serian las nuevas azadas? Si hablamos de coronelismo electrónico, podemos hablar, también, de clientelismo, patrimonialismo o municipalismo electrónico? La percepción de que el coronelismo tiene que ver con un periodo histórico, transparece en el ambiente de comunicaciones? A la luz de la literatura historiográfica relativa al coronelismo, intentamos revisar un conjunto de enunciados de este sistema y defender su pertinencia como herencia conceptual conveniente a la proposición de una categoria analítica para el modelo brasileño de las comunicaciones. Para eso, será necesario: contextualizar el coronelismo y su adopción en los análises comunicacionales, delimitar algunas fronteras, señalar algunas imprecisiones e inconsistencias frecuentes $y$, al final, especificar nuestra propuesta de cinco enunciados heredados del coronelismo para constituir el coronelismo electrónico.

Palabras-clave: Coronelismo electrônico, televisión, radiodifusión, mercado brasileño de comunicaciones.

\begin{abstract}
Is it possible to adapt the concept 'coronelismo' to the field of the communication just adding a 'electronic'? Could we say that the property of broadcasting media is similar to what land property was in the First Republic? Would radio and TV recievers be the new hoes? If we are speaking about electronic coronelismo, can we also speak about eletronic clientelism, 'mandonismo', patronage or municipality? The consideration that there is a historical limit to date the coronelismo is reflected at mass communications field? Enlighted by some historical analysis related to coronelismo, we are trying to rescue a group of statements of this system and to defend its pertinence as a convenient conceptual inheritance to the proposition of an analytical category for the Brazilian mass communications model. For that, it will be necessary: setting a context to coronelismo and its adoption at social communications analysis, delimiting some borders, pointing some current imprecisions and inconsistencies, and, finally, specify our proposal of five coronelismo inherited statements to constitute the electronic coronelismo.
\end{abstract}

Keywords: Electronic-"Coronelismo", television, broadcasting, brazilian communications market.

No limiar da década de 80 um repórter da Rádio Rural, de Concórdia-SC, abria espaço para o depoimento do ex-senador Atílio Fontana: "Senador, o microfone é todo seu"; o Senador, ciente das suas posses, externava: "não só o microfone, meu rapaz, mas a rádio toda". Este episódio foi narrado em matéria do Jornal do Brasil na qual denunciava- 
se o uso eleitoreiro de 104 estações de rádio e televisão, espalhadas por 16 estados, de propriedade de deputados, governadores, senadores ou ministros ${ }^{2}$ (Jornal do Brasil, 1980).

Em 1980 o processo de abertura política do regime militar estava dando os seus primeiros passos. Depois de quinze anos de bipartidarismo, a Reforma Partidária tinha sido aprovada em novembro de 1979. Os novos partidos começavam a ser articulados: a ARENA transformou-se em PDS e o MDB dividiu-se em PMDB, PP, PT, PDT e PTB. Também neste ano, foram liberadas as eleições diretas para governos estaduais. Durante todo o período militar os critérios de defesa e manutenção do regime tinham sido impressos nos mais variados aspectos da vida política nacional. A concentração partidária, através dos governadores, senadores e prefeitos 'biônicos' e da maioria do Congresso com representantes da Arena, deu o tom da distribuição das outorgas de radiodifusão para as elites políticas. Na reportagem do Jornal do Brasil supracitada, 81,73\% das estações de rádio e televisão mencionadas eram controladas por afiliados do PDS.

Desde a denúncia no Jornal do Brasil, em 1980, a expressão 'coronelismo eletrônico' tem sido usada com relativa freqüência na mídia para referir-se ao singular cenário recente brasileiro no qual deputados e senadores se tornaram proprietários de empresas concessionárias de rádio e televisão e, simultaneamente, participam das comissões legislativas que outorgam os serviços e regulam os meios de comunicação no país. Em momentos anteriores nos dedicamos, em parceria com Sérgio Capparelli (2002; 2005), ao estudo do coronelismo eletrônico como forma de manutenção das elites políticas. Como o ambiente referencial dos estudos da Economia Política da Comunicação tem se desenvolvido a partir dos modelos de comunicação das sociedades capitalistas avançadas, as categorias condicionadas centralmente pela mercantilização das práticas sociais não davam conta desse proeminente fenômeno nacional. $\mathrm{O}$ trabalho mais próximo desta perspectiva, em nível internacional, é o artigo no qual Daniel Hallin e Stylianos Papathanassopoulos discutem a relevância do clientelismo político como barreira à autonomia jornalística em sete países (2002). O clientelismo, por ser um conceito mais

2 JORNAL do Brasil. No ar, a voz do dono. In: VAN TILBURG, João Luis. Banco de Dados TV-Pesquisa. Online: documento n. 3636, 07 dez. 1980. Disponível em: <http://www.tvpesquisa.com.puc-rio.br/11119401.htm>. 
universal, esbarra na especificidade das práticas políticas da comunicação brasileira. Dando continuidade, ensaiamos algumas questões pertinentes à idéia de coronelismo eletrônico.

Este trabalho pretende contribuir para o avanço destas questões adotando a compreensão de Leal $(1997 ; 1980)$ de que o coronelismo deve ser entendido como um sistema que é perpassado por uma rede de relações entre poderes locais e federais. Á luz da literatura historiográfica relativa ao coronelismo, tentamos resgatar um conjunto de enunciados deste sistema e defender sua pertinência enquanto herança conceitual conveniente à proposição de uma categoria analítica para o modelo brasileiro de comunicações. Para isso, será necessário: contextualizar o coronelismo e sua adoção nas análises comunicacionais, delimitar algumas fronteiras, apontar algumas imprecisões e inconsistências corriqueiras, e, por fim, especificar nossa proposta da adoção de cinco enunciados herdados do coronelismo para constituir o coronelismo eletrônico. Definimos como enunciados hereditários do coronelismo:

1) a circunscrição a um momento de transição do sistema político nacional;

2) as relações clientelistas com alto grau de reciprocidade;

3) a debilidade da distinção entre interesses público e privado;

4) o controle dos meios de produção baseado no poder político em detrimento do poder econômico, e;

5) o isolamento da municipalidade.

\section{Do Coronelismo ao coronelismo eletrônico: aspectos constituintes da hereditariedade}

A expressão coronelismo foi definida por Victor Nunes Leal, no livro Coronelismo: enxada e voto, em 1949 (1997). O poder dos coronéis teve início no período colonial quando fazendeiros recebiam a patente militar para cumprir o papel de autoridade estatal nas regiões de difícil acesso, compondo a Guarda Nacional. A partir da instalação da chamada Primeira República (1889-1930), estes coronéis incrementaram sua estrutura de poder baseados num sistema eleitoral que não previa a votação secreta. A dependência dos trabalhadores rurais em relação aos coronéis e a possibilidade de conferência dos votos 
criaram uma situação na qual o 'voto de cabresto' era praticamente obrigatório. Desta forma, os coronéis municipais se aliavam às oligarquias estaduais, representadas principalmente pelos governadores, e estas ao Governo Federal, numa intensa rede de favores. Segundo Leal:

o 'coronelismo' é sobretudo um compromisso, uma troca de proveitos entre o poder público, progressivamente fortalecido, e a decadente influência social dos chefes locais, notadamente os senhores de terra [...] Desse compromisso fundamental resulta as características secundárias do sistema 'coronelista', como sejam, entre outras, o mandonismo, o filhotismo, o falseamento do voto, a desorganização dos serviços públicos locais (1997: 40).

Ao caracterizar o coronelismo como um momento de conexão entre poder público e poder privado, o autor enfatiza a fragilidade da municipalidade frente a um federalismo marcado por uma tendência altamente centralizadora do poder político. A especificidade deste momento, na obra de Leal, está caracterizada pela junção do advento da república à decadência econômica do setor agrícola.

Ao longo do século XIX, o poder rural foi abalado pela queda dos preços do açúcar e do algodão, na primeira metade do século; pelo desgaste econômico-político das convulsões internas nas diversas regiões; pelo fim da economia escravocrata (FURTADO, 2005: 95-147); e, principalmente, pela modernização do país com o crescimento do comércio e da indústria sob influência do estreitamento das relações com a Inglaterra. $\mathrm{O}$ fortalecimento de uma nova elite industrial era visto pelo Segundo Reinado como a melhor alternativa para economia nacional. Neste contexto,

a chamada elite agrária, forte e altiva nos seus latifúndios, some diante do ardente círculo dos negócios: ela está subordinada, pelos interesses da escravidão, ao "monopólio de outros monopólios comerciais"3 (...) o Segundo Reinado será o paraíso dos comerciantes, entre os quais se incluem os intermediários honrados e os especuladores prontos para o bote à presa, em aliança com o Tesouro (FAORO, 2001 : 500).

\footnotetext{
${ }^{3}$ BARBOSA, Rui. Relatório do Ministro da Fazenda. In: Obras Completas. Tomo II, v. 18, 1891 : 141 apud FAORO, 2001: 500.
} 
O conflito entre a modernização e o conservadorismo econômico fomentou uma importante crise comercial que levou à bancarrota importantes casas bancárias entre $1864 \mathrm{e}$ 1875. Conforme Sérgio Buarque de Holanda,

Esta crise foi o desfecho normal de uma situação rigorosamente insustentável nascida da ambição de vestir um país ainda preso à economia escravocrata com os trajes modernos de uma grande democracia burguesa. De certo modo, o malogro comercial de um Mauá4 também é indício eloqüente da radical incompatibilidade entre as formas de vida copiadas de nações socialmente mais avançadas, de um lado, e o patriarcalismo e personalismo fixados entre nós por uma tradição de origens seculares (1995: 79).

Desta forma, o coronelismo se refere a um momento da história brasileira no qual os fazendeiros utilizaram poderes alternativos à concentração econômica - o mandonismo, o filhotismo, o falseamento do voto - como uma moeda para negociar sua sobrevivência no comando do poder municipal e o Governo Federal, por sua vez, utilizava seus poderes patronais para negociar a coesão da recém-criada República Federativa Brasileira. Na criação dos governadores como elo entre a esfera federal e o município é que está datado o sistema coronelista.

O governo estadual garante, para baixo, o poder do coronel sobre seus dependentes e seus rivais, sobretudo cedendo-lhe o controle dos cargos públicos, desde o delegado de polícia até a professora primária. O coronel hipoteca seu apoio ao governo, sobretudo na forma de votos. Para cima, os governadores dão seu apoio ao presidente da República em troca de reconhecimento por parte deste de seu domínio no Estado (CARVALHO, 2005a : 132).

Coronelismo, Enxada e Voto pode ser considerado parte da bibliografia básica para os estudos históricos brasileiros. A adoção da obra, contudo, não foi instantânea. Segundo José Murilo de Carvalho, levou até o final da década de 1960 para o texto começar a circular em disciplinas universitárias e, após a segunda edição em 1975, é que

\footnotetext{
${ }^{4} \mathrm{O}$ autor refere-se a Irineu Evangelista de Sousa, Barão e Visconde de Mauá, importante empresário e um dos principais defensores do liberalismo no Brasil. Os negócios de Mauá iam desde concessões para a construção de estradas de ferro até o setor bancário. A decadência do empresário tem seu auge no período entre 1865, quando o banco Mauá se associa ao capital inglês para sair da crise, e 1871, quando ocorre o fechamento do banco Mauá, McGregor \& Co e sua posterior transformação em New London and Brazilian Bank. Em 1875 deu-se a falência do empresário.
} 
aumenta a frequência de trabalhos acadêmicos que inscrevem 'Coronelismo...' como referência (2005b). O texto mereceu diferentes apropriações conceituais ao longo dos anos (GRAHAM, 1990; JANOTTI, 1992; CARONE, 1973), além, naturalmente, de críticas ao próprio aparato conceitual de 'Coronelismo...' (PANG, 1979; GOMES; FERREIRA, 1989).

Nunes Leal retomou a discussão, no intuito de especificar sua análise, no sucinto artigo O coronelismo e o coronelismo de cada um (1980). Para Leal, as apropriações foram criando acepções e enfoques distintos do seu coronelismo (1980). Embora outros autores tenham revisado esta bibliografia de forma detalhada (PINTO, 1998; GOMES; FERREIRA, 1989), a retomada mais completa e rigorosa das variações semânticas em torno do coronelismo é aquela elaborada, em 1997, por José Murilo de Carvalho em Mandonismo, Coronelismo, Clientelismo: uma discussão conceitual. Para o autor, os conceitos relativos à temática vêm sendo adotados de maneira pouco consistente de forma que "o acúmulo de pesquisas passa a ter rendimento decrescente porque as idéias começam a girar em roda, sem conseguir avançar devido às confusões ou imprecisões conceituais" (2005a, 130). Basta um rápido levantamento das pesquisas para constatar, de fato, muita inconsistência e imprecisão ao tratar o inter-relacionamento entre conceitos como clientelismo, patrimonialismo e mandonismo e a sua relação com o coronelismo.

Nas políticas de comunicação brasileiras, por outro lado, nos governos democráticos subseqüentes ao período militar foram pontuadas por elementos que as diferenciaram da tendência global de aceitação automática da convergência dos meios. $\mathrm{Na}$ verdade, o período compreendido nos últimos vinte anos, operou um grande distanciamento entre o modelo brasileiro de comunicação e os modelos internacionais mais conhecidos. Inclui-se:

a) o detalhamento das lógicas clientelistas que transformou as outorgas municipais de rádio e televisão em moeda política no jogo federal;

b) o deslocamento, na regulação do setor, da centralidade do interesse privado, em detrimento do interesse público, para a centralidade do interesse político e/ou religioso, local ou regional, em detrimento do interesse econômico global ou nacional; 
c) a esdrúxula separação das velhas e novas tecnologias de comunicação em marcos regulatórios distintos (radiodifusão no âmbito do Ministério das Comunicações, e comunicações ${ }^{5}$ no âmbito da Agência Nacional de Telecomunicações);e,

d) a ausência de transparência sobre a estrutura de propriedade e de afiliação da radiodifusão nacional.

Este momento político específico do sistema de comunicação levou alguns analistas a buscar no 'Coronelismo' de Victor Nunes Leal a matriz analítica para o fenômeno comunicacional. Desse modo, chamamos de coronelismo eletrônico o sistema organizacional da recente estrutura brasileira de comunicações, baseado no compromisso recíproco entre poder nacional e poder local, configurando uma complexa rede de influências entre o poder público e o poder privado dos chefes locais, proprietários de meios de comunicação. Da mesma forma que no coronelismo, o coronelismo eletrônico, é $\mathrm{O}$

Resultado da superposição de formas desenvolvidas do regime representativo a uma estrutura econômica e social inadequada. Não é, pois, mera sobrevivência do poder privado (...) É antes uma forma peculiar de manifestação do poder privado, ou seja, uma adaptação em virtude da qual os resíduos do nosso antigo e exorbitante poder privado têm conseguido coexistir com um regime político de extensa base representativa (LEAL, 1997 : 40).

O primeiro trabalho, de natureza acadêmica, a adotar o termo coronelismo eletrônico foi a monografia de Célia Stadnik, intitulada $A$ bipótese do fenômeno do "Coronelismo eletrônico" e as ligações dos parlamentares federais e governadores com os meios de comunicação no Brasil (1991). Nas duas últimas décadas, os trabalhos adotando esta idéia se tornaram mais freqüentes ${ }^{6}$. Esta freqüência, no entanto, não reflete uma discussão conceitual. A maior parte destes trabalhos consiste de árduo trabalho empírico.

\footnotetext{
${ }^{5}$ A divisão opera uma separação conceitual entre televisão aberta, compreendida pela radiodifusão, e televisão por assinatura, compreendida junto com os demais serviços como Internet e telefonia. Há ainda outra separação que é a retirada do cinema da compreensão de meios de comunicação e a sua estratégica colocação no âmbito do Ministério da Cultura/Agência Nacional do Cinema.

${ }^{6}$ Por exemplo Bayma (2001, 2006); Capparelli e Lima (2004); Kaseker (2004); Lima, M. (2001); Lima, V. (2004, 2005, 2006); Luz (1997); Moura (2005); Pacheco (2001); Rebouças e Fadul (2005); Santos e Capparelli (2001, 2002, 2005).
} 
Quem se interessa em ter uma idéia, mesmo que vaga, da estrutura de distribuição das comunicações no país tem de lidar com um enigma similar aos enfrentados pelas personagens de literatura policial. As informações públicas são pulverizadas entre diversos arquivos $^{7}$, sistemas e portais $^{8}$; arquivos em formatos de difícil manipulação ${ }^{9}$, com informações imprecisas ${ }^{10}$, dados desatualizados ${ }^{11}$ e erros de registro ${ }^{12}$. Os esforços de investigação empírica ainda demandam buscas de registros em juntas comerciais, em ferramentas online ${ }^{13}$ e nos jornais locais, entre outros, na tentativa de estabelecer as conexões internas da extensa rede informal de compadrio que dá sustentação ao sistema de radiodifusão brasileiro.

Assim, a urgente necessidade de denúncia de práticas condenáveis na sociedade hodierna trouxe embutida a ausência de reflexão acerca da natureza e da constituição desta conceituação. Não se pretende, aqui, diminuir o valor das análises empíricas sobre a estrutura econômico-política das comunicações no Brasil. Pelo contrário, acreditamos que o manejo de dados quantitativos e de documentos primários é fundamental para evitar o desvio da realidade material perceptível em muitas análises baseadas unicamente em abstrações ou em modelos forâneos. O coronelismo eletrônico constitui, ao nosso ver, elemento cardinal para a compreensão da especificidade do sistema de comunicações brasileiro.

Falta, todavia, uma trilha. Primeiramente porque, apesar do esforço necessário para o levantamento, a preparação e a apresentação de dados quali-quantitativos, é nítida a

\footnotetext{
${ }^{7}$ Especialmente no que tange a documentos mais específicos, como contratos e propostas de outorgas, e anteriores à implantação da Anatel.

${ }^{8}$ Parte das informações consta do portal do Ministério das Comunicações, outra parte nos 34 sistemas interativos no portal da Anatel.

${ }^{9}$ Como é o caso das listas de acionistas, tornadas públicas pela primeira vez na história da radiodifusão brasileira em 2003, disponíveis em documentos de centenas de páginas no formato .pdf, relativo ao software Adobe Acrobat Reader.

${ }^{10} \mathrm{Na}$ lista das outorgas aparecem apenas as razões sociais das empresas e os nomes dos sócios, sem a distribuição percentual das cotas para cada empresa, sem o nome fantasia, sem a afiliação. ${ }^{11}$ Por exemplo, Pedro Affonso Collor de Mello, falecido em 1994, ainda figura nos quadros de sócios da Rádio Clube de Alagoas LTDA, detentora de duas outorgas de FM; da Rádio Gazeta de Alagoas LTDA, detentora de uma outorga de OM; e da TV Gazeta de Alagoas LTDA, segundo lista oficial do Ministério das Comunicações.

${ }^{12}$ É comum a presença de nomes com grafia errada.

${ }^{13}$ Tais como o Google.
} 
ausência de escopo teórico na produção em comunicação que dê conta do fenômeno. Também porque adaptações apressadas dos conceitos originais correm o risco de resultar em noções tão enviesadas quanto aquelas nas quais freqüentemente acusamos a fuga da realidade.

\section{Imprecisões comunicacionais: o coronel é eletrônico?}

Quando da morte de Victor Nunes Leal, em 1985, José Murilo de Carvalho já apontava "o perigo de [o "Coronelismo...] se tornar o clássico muito citado e mal lido" $\left(2005 b^{14}\right.$ : 382). Na adaptação do coronelismo para o coronelismo eletrônico os temores do autor chegam perto de ser confirmados. Por se tratar de assunto pouco discutido dentro dos cursos de graduação e pós-graduação em comunicação, há uma série de equívocos a descaracterizar a riqueza da análise original de Leal.

Parte da descaracterização do coronelismo deve-se à apropriação errônea da expressão pelo senso comum. Percebe-se, na gramática do tema, um entendimento de que o sufixo ‘ismo’ forma a ação originada no nome próprio, logo, coronelismo seria o sistema que designa as ações dos coronéis. Derivado desse, o coronelismo eletrônico comportaria as ações dos coronéis nos meios eletrônicos de comunicação.

Essa concepção retira do coronelismo a natureza de sistema, atribuída por Leal, além de fundir, sem qualquer distinção, coronel e coronelismo. Há quem estenda a conceituação mais ainda, transformando o exercício do poder em coronelismo. “(...) deter uma concessão de televisão significa estar mais próximo do exercício do poder. A expressão 'coronelismo eletrônico' já pode ser usada sem as aspas. É fato corriqueiro, basta olhar em torno" (CUNHA, 2002 : 217). Em muitos trabalhos, nota-se, também, dificuldade para entender quem é o coronel de quem fala Leal em 'Coronelismo...' e o que definiria este ator no cenário comunicacional brasileiro.

A adaptação apressada primordial é a que se reporta ao coronel eletrônico como toda personagem que simultaneamente exerce mandato eletivo e é proprietária de meios de

\footnotetext{
14 Originalmente publicado em Dados: Revista de Ciências Sociais. Rio de Janeiro: v. 28, n. 2, 1985. pp. 141-142.
} 
comunicação. Por derivação, seria como reportar ao coronel como qualquer proprietário rural exercendo mandato eletivo. O ser disforme e descomunal oriundo de tal ilação não encontra alicerce na obra de Leal, nem em qualquer bibliografia de referência sobre o coronelismo.

Para observar a fidelidade autoral, a ruptura com essa habitual noção generalista deve estar na raiz da análise que pretenda a adoção do coronelismo eletrônico na gramática comunicacional. Já no capítulo primeiro de 'Coronelismo...' se encontra a negação do caráter absoluto ao coronel: "O aspecto que salta aos olhos é o da liderança, com a figura do 'coronel' ocupando o lugar de maior destaque. Os chefes políticos municipais nem sempre são autênticos 'coronéis"' (1997 : 41). Embora a expressividade da atividade rural no Brasil da Primeira República fosse incontestável, o coronel poderia ser um burocrata, comerciante, profissional liberal ou até um padre. Nem precisa deter cargo eletivo. O que caracteriza o coronel é, em resumo, o status de comando numa determinada região.

Qualquer que seja, entretanto, o chefe municipal, o elemento primário desse tipo de liderança é o "coronel", que comanda discricionariamente um lote considerável de votos de cabresto. A força eleitoral empresta-lhe prestígio político, natural coroamento de sua privilegiada situação econômica e social de dono de terras. Dentro da esfera própria da influência, o "coronel" como que resume em sua pessoa, sem substituí-las, importantes instituições sociais. Exerce, por exemplo, uma ampla jurisdição sobre seus dependentes, compondo rixas e desavenças e proferindo, às vezes, verdadeiros arbitramentos, que os interessados respeitam. Também enfeixam em suas mãos, com ou sem caráter oficial, extensas funções policiais, de que freqüentemente se desincumbe com a sua pura ascendência social, mas que eventualmente pode tornar efetivas com o auxílio de empregados, agregados ou capangas (LEAL, 1997, 42).

A propriedade de meios de comunicação pode ser considerada potente instrumento de força eleitoral, contudo, o raio de ação do coronel é diferenciado do de um radiodifusor que conquista votações expressivas. Não se pode incluir na mesma categoria figuras como Antonio Carlos Magalhães e Hélio Costa apenas porque ambos são radiodifusores que exercem mandatos eletivos e ocuparam o cargo de Ministro das Comunicações. Eles desempenham papéis diferentes no sistema de coronelismo eletrônico. Ainda que se perceba traços clientelistas em ambas atuações públicas, embora participem da mesma rede de compadrio que tem dado forma ao que chamamos de coronelismo 
eletrônico, não há um 'Helismo' ou um 'Costismo' atuando como chefia política, arbitragem social e fonte de coerção em Minas Gerais. Se os candidatos apoiados por Hélio Costa perdessem as eleições para governador e senador, a manchete do dia seguinte no jornal de Barbacena dificilmente seria "Clima de decepção predomina entre os eleitores"15.

É também usual a confusão entre mandonismo e coronelismo, como se fossem dois nomes para o mesmo fenômeno (CARONE, 1973; PANG, 1979). Essa pode ser a degeneração mais nociva à análise já que induz à figura do coronel como um senhor absoluto, quase mitológico, que inverte a ordem conceitual. O coronelismo se inscreve como um momento particular do mandonismo "exatamente aquele em que os mandões começam a perder força e têm de recorrer ao governo" (CARVALHO, 2005a : 133). Mandonismo, para Victor Nunes Leal e para José Murilo de Carvalho, é mais abrangente, ocorre em diversos momentos e diversos lugares, se aproxima mais da idéia de caciquismo, por exemplo. Leal contradiz com veemência esta sinonímia:

Não há uma palavra sequer no meu livro pela qual se pudesse atribuir o status de senhor absoluto ao coronel (...) Em nenhum momento repito - chamei o coronel de senhor absoluto. Nem jamais me passou isso pela cabeça. Ao contrário, divergindo da noção corrente, digamos, da noção vulgar de coronelismo - que punha ênfase no mandonismo, apresentando sempre o coronel como um homem valente, destemido, desafiador da autoridade pública, um homem rico, poderoso, condutor de exércitos privados -, o que procurei acentuar, como característica dominante na Primeira República, foi, ao contrário, a decadência sócio-econômica dos senhores rurais - montados numa agricultura decadente, numa agricultura depredadora -, incapazes, portanto, de solucionar os próprios problemas que a agricultura colocava para eles. Esse personagem da vida local, o que me pareceu sobretudo foi um homem mais fraco do que forte $(1980: 13)$.

Outra descaracterização conceitual está na expressão 'coronel eletrônico'. Não há razão evidente para inserir os meios de comunicação, ou a propriedade deles, na figura do coronel. A propriedade de veículos de comunicação é, isto sim, parte do controle dos meios de produção, característica fundamental daquilo que queremos definir como um sistema de coronelismo eletrônico. Logo, não é o coronel que é eletrônico, mas o coronelismo. A natureza mutante do coronel é largamente reconhecida (CARVALHO,

15 Correio da Bahia, online, 02 out. 2006. Disponível em: < http://www.correiodabahia.com.br/aquisalvador/noticia.asp?codigo $=113559$ >. 
2001, 2005a, 2005b; CARONE, 1973, FAORO, 2001; GRAHAM, 1990; LEAL, 1997; PANG, 1979; VILAÇA; ALBUQUERQUE, 2003). A morte de Francisco Heráclio do Rego, coronel Chico Heráclio, em 1974 não extinguiu a espécie. O coronel já existia antes do coronelismo e continuou a existir depois dele. Ele certamente passou por metamorfoses modernizantes, mas "vive da sobrevivência de traços, práticas e valores remanscentes dos velhos tempos" (CARVALHO, 2001 : 3). E segue sendo simplesmente coronel, não coronel eletrônico nem neocoronel nem cibercoronel.

As limitações de espaço deste trabalho não permitem uma profunda revisão das variações e análises realizadas sobre comunicação de massa e coronelismo. Vamos nos ater a algumas dessas variações para observar a pertinência deste ou daquele conceito ao universo das comunicações. Apresentamos agora os enunciados que propomos tomar como herança do coronelismo para embasar nossas análises. O primeiro enunciado que necessita especificidade para corporificar a concepção de coronelismo eletrônico é a circunscrição temporal do coronelismo a um momento de transição do sistema político nacional.

\section{Herança n. 1: O coronelismo é um fenômeno datado. O coronelismo eletrônico também?}

Não há consenso a respeito da continuidade do coronelismo. O mais enfático defensor da circunscrição do fenômeno num período específico é José Murilo de Carvalho. Para Carvalho (2005a), o coronelismo é restrito ao período da Primeira República. O fim do coronelismo é datado por Carvalho em dois momentos: um simbólico, quando da prisão dos grandes coronéis baianos pelo Governo Provisório, em 1930, e outro, de fato, no momento da implantação do Estado Novo e da queda de Flores da Cunha, caudilho gaúcho, no Rio Grande do Sul, em 1937. Carvalho não absolve nem a retomada posterior do assunto por Leal:

O coronelismo é fase do processo mais longo de relacionamento entre os fazendeiros e o governo. O coronelismo não existiu antes dessa fase e não existe depois dela (...) O próprio Leal é incoerente ao sugerir um renascimento do coronelismo embutido na tentativa dos presidentes militares de estabelecer contato direto entre o governo federal e os municípios, passando por cima dos governadores (Leal, 
1980, p. 14). A nova situação nada tinha a ver com a que descreveu em sua obra clássica (2005a : 132).

Leal foi menos enfático no “Coronelismo...", embora convencido de que o voto secreto e a vitalização dos municípios pudesse enfraquecer o coronelismo, para ele, o fim do coronelismo está condicionado à reformulação da estrutura agrária (1997 : 285). Os parágrafos finais do livro demonstram o ceticismo do autor:

Não podemos negar que o "coronelismo" corresponde a uma quadra da evolução política do nosso povo, que deixa muito a desejar. Tivéssemos maior dose de espírito público e as coisas certamente se passariam de outra forma. Por isso, todas as medidas de moralização da vida pública nacional são indiscutivelmente úteis e merecem o aplauso de quantos anseiam pela elevação do nível político do Brasil. Mas não tenhamos demasiadas ilusões. A pobreza do povo, especialmente da população rural, e, em conseqüência, o seu atraso cívico e intelectual constituirão sério obstáculo às intenções mais nobres (1997: 287).

Contraditoriamente, a segunda edição de 'Coronelismo...', autorizada pelo autor somente em 1975, trazia um prefácio de Barbosa Lima Sobrinho tratando o coronelismo como um fenômeno contínuo:

A faixa do prestígio e da influência do "coronel" vai minguando, pela presença de outras forças, em torno das quais se vão estruturando novas lideranças (...) $\mathrm{O}$ que não quer dizer que tenha acabado o "coronelismo" (...) Que importa que o "coronel" tenha passado a doutor? Ou que a fazenda se tenha transformado em fábrica? Ou que seus auxiliares tenham passado a assessores ou a técnicos? A realidade subjacente não se altera, nas áreas a que ficou confinada. O fenômeno do "coronelismo" persiste, até mesmo como reflexo de uma situação de distribuição de renda, em que a condição econômica dos proletários mal chega a distinguir-se da miséria (LEAL, 1997 : 18).

O alargamento temporal produzido por Barbosa Lima Sobrinho se repete em outros autores, como Vilaça e Albuquerque (2003), que datam a decadência do coronelismo nos anos 1960. Na transposição do conceito para a atualidade, através do adendo 'eletrônico', ocorre alargamento semelhante. Mesmo Victor Nunes Leal, posteriormente circunscreveu sua análise na Primeira República, mas resgatou a possibilidade de continuidade ao se referir ao processo de desagregação do coronelismo como algo em andamento (1980 : 14). A rigidez temporal que aparece na análise de 
Carvalho deve ser entendida como reflexo da premência da precisão conceitual. Retirar do coronelismo sua limitação temporal é descaracterizá-lo.

Ao longo do texto de Leal fica clara a inscrição temporal do coronelismo. Os coronéis existiam antes da Primeira República e continuaram existindo depois dela. O fenômeno, na concepção do autor, referia-se à inter-relação dos elementos componentes das relações de poder num momento específico de transição entre duas estruturas políticas diferenciadas.

Seria, porém, errôneo identificar o patriarcalismo colonial com o "coronelismo" (...) também não teria propósito dar este nome à poderosa influência que, modernamente, os grandes grupos econômicos exercem sobre o Estado (...) não se pode, pois, reduzir o "coronelismo" a simples afirmação anormal do poder privado. É também isso, mas não é somente isso (LEAL, 1997 : 276).

No ordenamento das relações pertinentes ao coronelismo o papel central é o da articulação entre o município e a federação. Esse sistema nacional de poder específico representava a recomposição do jogo de forças na passagem brasileira da monarquia para a república. "O coronel entrou na análise por ser parte do sistema, mas o que mais me preocupava era o sistema, a estrutura e a maneira pelas quais as relações de poder se desenvolviam na Primeira República, a partir do município” (LEAL, 1980 : 13).

$\mathrm{Na}$ adaptação do coronelismo, para atender às necessidades da análise do fenômeno comunicacional brasileiro, é necessário corrigir a idéia de que o coronelismo é prática contínua que apenas se atualiza a partir da inserção dos meios de comunicação. Diferente do que dissemos com Capparelli, em 2002, e diferente do que disse Barbosa Lima Sobrinho, no prefácio à segunda edição do 'Coronelismo...'(LEAL, 1997 : 19), o coronelismo não continuou sob novas bases. Há um vácuo no sistema de permuta entre os poderes locais e federais no período compreendido entre o Estado Novo e a ditadura militar. A suspensão de eleições por Getúlio $\operatorname{Vargas}^{16}$ e pelos militares ${ }^{17}$ eliminou o voto como moeda de troca. É inegável também que a urbanização ocorrida desde o fim da

\footnotetext{
16 Entre 1937 e 1945 para todos os cargos.

${ }_{17}$ Entre 1965 e 1988 para presidente, entre 1966 e 1982 para governador, e, entre 1966 e 1985 para prefeitos das capitais.
} 
Primeira República operou um nível maior de democratização e cidadania no país. Se os coronéis seguiram existindo (CARVALHO, 2001; VILAÇA, ALBUQUERQUE, 2003), estiveram em posição diretamente subordinada em relação ao poder federal.

A retomada semântica que propomos aqui atém o coronelismo eletrônico a um período histórico semelhante àquele estudado por Leal, um momento de transição entre dois modelos políticos: a ditadura e a democracia. A semelhança entre os dois momentos históricos foi reconhecida por José Murilo de Carvalho no necrológio de Leal:

Victor Nunes desapareceu num contexto político de democratização, semelhante àquele em que escrevera Coronelismo. Sua preocupação em 1948 é a mesma que domina grande parte do País nos dias de hoje: como proceder à construção social da cidadania (...). As circunstâncias que presidem ao esforço de construir a cidadania hoje estão modificadas, mas não deixa de ser um elogio a mais a Victor Nunes, ao mesmo tempo que um comentário melancólico sobre o País, o fato de que o grande obstáculo que via há 37 anos atrás - a estrutura agrária obsoleta e oligárquica - permaneça ainda hoje tema que desperta as mesmas histéricas reações (2005b : 382-383).

\section{Heranças n. 2, 3 e 4: Coronel, Governo e Meios de Comunicação}

Acreditamos que a conceituação de clientelismo - bem como a amplitude da sua aplicação para além dos domínios do coronelismo, e, especialmente, a sua concernência para o coronelismo eletrônico - já foi suficientemente detalhada na análise de Israel Bayma (2006), em nosso texto anterior com Sérgio Capparelli (2005) e em nossa tese doutoral (2004). As relações de barganha clientelística com alto grau de reciprocidade, pertinentes ao coronelismo eletrônico, também foram profundamente documentadas nas análises de Paulino Motter (1994), Israel Bayma (2001) e Venício Artur de Lima (2001; 2004; 2005; 2006), entre outros.

Outro ponto em que não nos deteremos por muito tempo é a debilidade da distinção entre os interesses público e privado. No campo da história política, esta debilidade foi abordada em detalhe por Sérgio Buarque de Holanda, no Raízes do Brasil, de 1936. A preservação de certos traços de promiscuidade nas relações entre interesses privados e poder público no ambiente comunicacional atual está discutida de forma satisfatória no trabalho de Regina Luna Santos de Souza (2005) e de Paulino Motter (1994). 
A desorganização dos serviços públicos locais (LEAL, 1997: 41) é, depois do clientelismo, a parte mais propagada do coronelismo e do coronelismo eletrônico. A centralização do controle dos meios de comunicação na esfera federal constitui a moeda do governo na barganha pelos favores desejados. Devemos, porém, acrescentar que, para Leal, esta debilidade interessa mais no sentido de ressaltar a fragilidade econômica do coronel no momento do coronelismo. $\mathrm{O}$ autor pretende fundamentalmente diferenciar o poder privado do coronelismo das noções de poder privado pertinentes a outras conjunturas da história brasileira. Segundo Leal, o coronelismo não corresponde

à fase áurea do privatismo: o sistema peculiar a esse estádio, já superado no Brasil, é o patriarcalismo, com a concentração do poder econômico, social e político no grupo parental. O "coronelismo" pressupõe, ao contrário, a decadência do poder privado e funciona como processo de conservação de seu conteúdo residual (LEAL, 1997 :276).

Proporcionalmente, o momento mais feliz para os chefes locais proprietários de radiodifusão foi o período da ditadura militar. Não havia TV a cabo, por microondas, por satélite nem Internet a servir de concorrente, nem as polpudas verbas das majors internacionais a seduzir ministros e presidentes. No plano político, não havia liberdade partidária e controle externo nem se cogitavam questões fortalecidas pela democracia como cidadania e direito do consumidor. Ao destacar a fragilidade do poder privado no coronelismo, Leal se aproxima do nosso próximo enunciado hereditário: a busca do controle dos meios de produção baseada no poder político em detrimento do poder econômico. Esta característica tem duas propriedades secundárias: a) a precariedade econômica do coronel, e, b) a terra e a radiodifusão como meios de produção.

A modernização imposta pelas tendências liberais que atiçaram a proclamação da república foi fundamental para o declínio do senhor rural. O sistema produtivo açucareiro e algodoeiro, que compreendia grande parte dos coronéis, estava fundado em bases coloniais nas quais o fazendeiro tinha pouca participação na estrutura de comércio dos produtos, executada em Portugal ou na Holanda.

Assim isolados, os homens que dirigiam a produção não puderam desenvolver uma consciência clara de seus próprios interesses. Com o tempo, foram perdendo sua verdadeira função econômica, e as tarefas 
diretivas passaram a constituir simples rotina executada por feitores e outros empregados. Compreende-se, portanto, que os antigos empresários hajam involú́do numa classe de rentistas ociosos, fechados num pequeno ambiente rural, cuja expressão final será o patriarca bonachão que tanto espaço ocupa nos ensaios dos sociólogos nordestinos do século XX. A separação de Portugal não trouxe modificações fundamentais, permanecendo a etapa produtiva isolada e dirigida por homens de espírito puramente ruralista (FURTADO, $2005: 121-122)$.

A ausência de expressividade econômica frente ao crescimento de elites comerciais e industriais impeliu o coronel à valorização de seu poder político. Semelhante situação ocorre no coronelismo eletrônico. As empresas de comunicação controladas pelos coronéis não atendem às lógicas usuais de mercado. Os veículos de comunicação sob sua influência são financiados por anúncios publicitários governamentais e os veículos de comunicação governamentais sob sua gestão pelas verbas públicas. A direção das empresas no âmbito local e regional é, usualmente, cedida aos parentes ou afiliados, prescindindo dos valores do capitalismo ocidental como, por exemplo, eficiência. Os serviços de comunicação oferecidos pelas empresas dos coronéis são pobres, não têm condições de competitividade em termos de qualidade de conteúdo ou de distribuição eficaz. Precariedade econômica herdada do coronelismo de Leal.

Há, é certo, muitos fazendeiros abastados e prósperos, mas o comum, nos dias de hoje, é o fazendeiro apenas "remediado": gente que tem propriedades e negócios, mas não possui disponibilidades financeiras; que tem o gado sob penhor ou a terra hipotecada; que regateia taxas e impostos, pleiteando condescendência fiscal; que corteja os bancos e demais credores, para poder prosseguir em suas atividades lucrativas (LEAL, 1997 : 43).

A aliança entre afiliada e cabeça-de-rede tem dupla função: garante a oferta de programação - conseqüentemente, garante a audiência - sem dispender muitos recursos e garante a máquina pública atuando em prol dos radiodifusores. A afiliação das empresas dos coronéis é de extrema valia para o decadente empresariado de comunicações brasileiro. Funciona, em grande medida, como barreira à entrada dos interesses convergentes das empresas internacionais no cenário nacional. Ratifica esta assertiva a bravata do vicepresidente de relações institucionais da TV Globo, Evandro Guimarães, ressaltando o impedimento constitucional para que as empresas de telecomunicações ofereçam 
programação audiovisual, disse: "se a Constituição é um problema, acho que as empresas de telecomunicações devem tentar mudá-la. Vamos ver se há força política para isso" "18. Este traço do coronelismo eletrônico, a aliança entre empresariado nacional e coronéis locais, não é perceptível como relevante na bibliografia sobre coronelismo.

A debilidade econômica dos coronéis não quer dizer que não concentrem renda. Regularmente, os negócios - hoje mais diversificados que na Primeira República - incluem faculdades, construtoras, fornecedoras de alimento, enfim, uma estrutura de serviços terceirizados prestados aos governos municipais, estaduais ou federal. Mas os coronéis são economicamente inferiores aos capitalistas. Boa parte dos negócios a eles relacionados não é lucrativa por si, mas pela pujança e pela intensa rede clientelista de que se serve o coronelismo eletrônico.

Muitos chefes municipais, mesmo quando participam da representação política estadual ou federal, costumam ser tributários de outros, que já galgaram, pelas relações de parentesco ou amizade, pelos dotes pessoais, pelos conchavos ou pelo simples acaso das circunstâncias, a posição de chefes de grupos ou correntes, no caminho da liderança estadual ou federal. Mas em todos esses graus da escala política impera, como não podia deixar de ser, o sistema de reciprocidade, e todo o edifício vai assentar na base, que o "coronel", fortalecido pelo entendimento que existe entre ele e a situação política dominante em seu Estado, através dos chefes intermediários (LEAL, 1997 : 64).

A transição para a democracia coincidiu com o período de inovação tecnológica nas comunicações e com a expansão do mercado global. Os custos necessários para oferecer serviços diferenciados como televisão por assinatura e provimento de Internet são proibitivos ao coronel. Por outro lado, a fase da multiplicidade da oferta dos serviços comunicacionais (BRITTOS, 1999) constitui ameaça perene ao espectro de influência dos coronéis. A possibilidade de diminuição de seu poder fez com que ele assumisse um papel diferencial como um intermediário entre o poder federal e o setor empresarial. Esta é sua condição de sobrevivência neste momento histórico.

Atribui-se ao domínio dos recursos de produção, mais usualmente à posse da terra, a ascendência do coronel nos municípios. O valor alegórico da terra é formador desse

\footnotetext{
18 Teles e Tevês pregam a sinergia, mas exigem reservas. Tela Viva News. Boletim distribuído por
} correio eletrônico em 09 fev. 2006. 
pressuposto. A imagem que perdura do proprietário rural é a imagem da riqueza, mesmo no atual Brasil industrializado, mesmo que essa propriedade esteja afundada em dívidas. "Ocorre que o coronel não manda porque tem riqueza, mas manda porque se the reconhece esse poder, num pacto não escrito" (FAORO, 2001 : 700). Este valor alegórico encontra farto berço de dominação na miserável população rural.

O roceiro vê sempre no "coronel" um homem rico, ainda que não o seja; rico, em comparação com sua pobreza sem remédio. Além do mais, no meio rural, é o proprietário de terra ou de gado quem tem meios de obter financiamentos. Para isso muito concorre seu prestígio político, pelas notórias ligações dos nossos bancos. É, pois, para o próprio "coronel" que o roceiro apela nos momentos de apertura (...) completamente analfabeto, ou quase, sem assistência médica, não lendo jornais, nem revistas, nas quais se limita a ver as figuras, o trabalhador rural, a não ser em casos esporádicos, tem o patrão na conta de benfeitor. E é dele, na verdade, que recebe os únicos favores que sua obscura existência conhece. Em sua situação, seria ilusório pretender que esse novo pária tivesse consciência do seu direito à uma vida melhor e lutasse por ele com independência cívica (LEAL, 1997, 43-44).

Esta é a herança que encontra menor dificuldade de transposição neste nosso esforço. No coronelismo eletrônico, a radiodifusão ocupa o lugar da terra de forma mais enfática por conta da centralidade midiática nas sociedades modernas. Como afirmam Graham Murdock e Peter Golding,

The range of interpretive frameworks, the ideas, concepts, facts and arguments which people use to make sense of their lives, are to a great extent dependent on media output, both fictional and non-fictional. Yet the frameworks offered are necessarily articulated with the nexus of interests producing them, and in this sense all information is ideology. To describe and explicate these interests is not to suggest a deterministic relationship, but to map the limits within wich the production of mediated culture can operate $(1974: 226)$.

A compreensão das referências que elaboram a construção de sentidos na sociedade está intimamente relacionada à compreensão das forças que ligam os indivíduos em relações sociais simétricas ou assimétricas. Neste viés, o domínio dos espaços de debate público mostra-se uma das mais relevantes ferramentas de persuasão social. A dominação pelos coronéis dos principais meios de comunicação nas esferas locais e regionais configura uma barreira à prática de cidadania no país. 
Hoje ainda, tal qual no século XIX, nosso liberalismo estabelece um limite claro para seu avanço democrático: o limite da escravidão. Lá, o povo era privado da sua liberdade no sentido mais absoluto; aqui, a privação, ainda que relativa, pode ser quase tão cruel, pois um homem privado da informação continua a ser, de algum modo, escravo, pois escravo é todo aquele que não pode se apresentar diante do outro como verdadeiro cidadão. E cidadania não há sem acesso à informação. (RAMOS, 1998).

É importante ressaltar entendimento de que os meios de comunicação e, consequentemente, seus produtos não podem estar desvinculados das condições de acesso. Como diz Morley:

Si bien el consumo puede considerarse siempre un proceso activo, no podemos olvidar que también es un proceso que siempre se desarrolla dentro de restricciones estructurales (o contra ellas). Esta es su dialéctica. Es preciso indagar entonces la variedad de esos procesos fundamentales y el modo en que los 'elaboran' las personas situadas en diferentes posiciones sociales y culturales. El aspecto que debe importarnos es la distribución social y las formas materiales y simbólicas del 'capital' con el que el consumo se logra (o 'performa') (MORLEY, 1996 : 317).

Se a terra no coronelismo servia ao coronel como instrumento de ampliação da sua influência, a radiodifusão no coronelismo eletrônico é ainda mais eficiente: serve para difundir a imagem protetora do coronel, serve para controlar as informações que chegam ao eleitorado e serve, por fim, para atacar os inimigos. Estas funções da radiodifusão justificam, para o coronel, a busca do controle desses meios e o cuidado para deixar seus inimigos longe deles.

\section{Herança final: a incrível batalha do coronelismo eletrônico local contra a convergência global}

A oferta de novas tecnologias de comunicação, a globalização e a democratização da sociedade podem desarticular o coronelismo eletrônico, por isso, o coronel se aferra à posse da radiodifusão. Ao mesmo tempo, busca alianças com os empresários nacionais para receber conteúdo de qualidade oferecendo uma barreira aos grupos internacionais. $\mathrm{O}$ isolamento dos municípios em relação aos grandes centros representa aqui uma última herança do coronelismo relevante para a compreensão do coronelismo eletrônico. 
Conquanto suas conseqüências se projetem sobre toda a vida política do país, o "coronelismo" atua no reduzido cenário do governo local. Seu habitat são os municípios do interior, o que equivale a dizer os municípios rurais, ou predominantemente rurais; sua vitalidade é inversamente proporcional ao desenvolvimento das atividades urbanas, como sejam o comércio e a indústria. Conseqüentemente, o isolamento é fator importante na formação e manutenção do fenômeno (LEAL, 1997 : 275).

José Murilo de Carvalho relativiza a aposta de Leal na urbanização como elemento destruidor do coronelismo. Embora o país tenha se urbanizado, "não mudaram a pobreza, a desigualdade e, até recentemente, o nível educacional" (2001 : 4). Do nosso ponto de vista, as proporções continentais do país, a concentração da capacidade de consumo nos poucos grandes centros urbanos e excessiva centralização do federalismo amparam o coronelismo eletrônico.

Primeiro, é muito difícil ao Estado fazer-se presente nas distintas regiões brasileiras. Segundo, num sistema de comunicações que historicamente privilegia interesses comerciais, em prejuízo do interesse público, pequenos municípios em regiões inóspitas têm pouco ou nenhum valor de interesse. Terceiro, a necessidade de reportar-se ao governo federal para oferecer serviços de comunicações facilita a troca de favores entre o governo federal e os coronéis. A representatividade do município pode ser observada pela expressividade do serviço de radiodifusão sob controle das prefeituras. Em 2004, um terço das estações retransmissoras de televisão brasileiras eram operadas por 1.676 prefeituras (Santos, 2004). Como a retransmissão de televisão depende apenas de permissão direta do Ministério das Comunicações, está garantida a via de circulação do coronelismo eletrônico.

Segundo Graham Murdock, nas sociedades capitalistas modernas, o papel das comunicações está em conectar o sistema produtivo, baseado na propriedade privada, ao sistema político que pressupõe uma cidadania cuja participação social efetiva depende, em parte, do acesso à maior gama possível de informação (1997 : 311). O problema estaria em equacionar como um sistema de comunicações dominado pela propriedade privada poderia garantir a diversidade de informação requerida para uma cidadania efetiva.

Contudo, a interconexão definida por Murdock permite apenas um retrato panorâmico. $\mathrm{Na}$ análise de casos específicos, sua aplicação necessita de outros focos de 
iluminação para que se possam delinear distintos contornos possíveis. No caso brasileiro, em alguns momentos, é fato, essas forças se complementam e integram um mesmo sistema. Em outros momentos, contraditoriamente, opõem-se e parecem integrar sistemas distintos. $\mathrm{Na}$ última década, as contradições entre as previsões relacionadas às novas tecnologias, à globalização e à re-regulamentação do setor frente à estrutura anteriormente consolidada se tornaram mais explícitas.

Há uma intensa disputa em curso. De um lado, nas grandes cidades, temos um processo de convergência das comunicações globalizado, no qual a digitalização e a fragmentação/diversificação parecem ser o único futuro provável, e, contraditoriamente, na maior parte do País, temos a resistência do coronelismo eletrônico e o espectro tantas vezes dado como desaparecido.

O coronel de hoje não vive num sistema coronelista que envolvia os três níveis de governo, não derruba governadores, não tem seu poder baseado na posse da terra e no controle da população rural. Mas mantém do antigo coronel a arrogância e a prepotência no trato com os adversários, a inadaptação às regras da convivência democrática, a convicção de estar acima da lei, a incapacidade de distinguir o público do privado, o uso do poder para conseguir empregos, contratos, financiamentos, subsídios e outros favores para enriquecimento próprio e da parentela. Tempera tudo isso com o molho do paternalismo e do clientelismo distribuindo as sobras das benesses públicas de que se apropria. Habilidoso, ele pode usar máscaras, como a do líder populista, ou do campeão da moralidade. Para conseguir tudo isso, conta hoje, como contava ontem, com a conivência dos governos estadual e federal, prontos a comprar seu apoio para manter a base de sustentação, fazer aprovar leis, evitar investigações indesejáveis. Nesse sentido, o novo coronel é parte de um sistema clientelístico nacional (CARVALHO, 2001: 3).

Assim, a discussão sobre as mudanças nas comunicações carece de relativização e especificidade. A reestruturação de um modelo comunicacional nacional, contudo, está profundamente condicionada à vontade de reestruturação e inovação dos próprios atores que compõem este ambiente. 


\section{Referências Bibliográficas:}

BAYMA, Israel F.C. A concentração da propriedade dos meios de comunicação no Brasil. Eptic. Revista Electónica Internacional de Economía de las Tecnologías de la Información y de la Comunicación., www.epctic.com.br, pp. 140-172, 2001.

Financiamento eleitoral pelo setor de comunicação nas eleições de 1998, 2000, 2002 e 2004: uma contribuição ao estudo do fenômeno do clientelismo político nos meios de comunicação no Brasil. Colóquio Internacional 2006. XXIX Congresso Brasileiro de Ciências da Comunicação - INTERCOM. Brasília: 2006.

BRITTOS, Valério. A televisão no Brasil, hoje: a multiplicidade da oferta. Comunicação \& Sociedade, São Bernardo do Campo, n. 31, pp. 934, 1. sem.1999.

BUARQUE DE HOLANDA, Sérgio. Raízes do Brasil. São Paulo: Companhia das Letras, 1995. 26 ed.

CALABRESE, Andrew. Toward a Political Economy of Culture. In: CALABRESE, Andrew; SPARKS, Collin (orgs). Toward a Political Economy of Culture: capitalism and communication in the Twenty-first Century. Londres: Rowan \& Littlefield, 2003. 1 ed.

CAPPARELLI, Sérgio; SANTOS, Suzy. Coronéis eletrônicos, voto e censura prospectiva. Cultura Vozes, Petrópolis, v. 96, n. 4, pp. 14-24, 2002.

CAPARELLI, Sérgio; LIMA, Venício. Comunicação\&televisão: Os desafios da pósglobalização. São Paulo: Hacker Editores, 2004.

CARONE, Edgard. A Primeira República (1989-1930): Texto e Contexto. São Paulo: Difusão Européia do Livro, 1973. 2 ed.

CARVALHO, José Murilo de. As metamorfoses do coronel. Jornal do Brasil. Rio de Janeiro: 06 mai. 2001. Disponível em:

<http://www.ppghis.ifcs.ufrj.br/media/carvalho_metamorfoses_coronel.pdf $>$.

In Memorian - Victor Nunes Leal (1914-1985). In: Pontos e

Bordados: escritos de história e política. Belo Horizonte: Editora UFMG, 2005b. pp. 381-383. 1 ed.

Mandonismo, Coronelismo, Clientelismo: uma discussão conceitual. In: Pontos e Bordados: escritos de história e política. Belo Horizonte: Editora UFMG, 2005a. p-130-155. 1 ed.

CUNHA, Paulo José. Televisão e poder no Brasil. MOTTA, Luiz Gonzaga (org.). Imprensa e Poder. Brasília: UnB/Imprensa Oficial de SP, 2002. pp. 217224. 1 ed.

FAORO, Raymundo. Os donos do poder. Rio de Janeiro: Globo, 2001.3 ed.

FURTADO, Celso. Formação Econômica do Brasil. São Paulo: Editora Nacional, 2005. 32 ed. 
GOMES, Angela de Castro; FERREIRA, Marieta de Moraes. Primeira República: um balanço historiográfico. Estudos Historiográficos. Rio de Janeiro: CPDOC-FGV, v. 2, n.4, 1989, pp. 244-280. Disponível em: <http://www.cpdoc.fgv.br/revista/arq/60.pdf>. Acesso em 12 set. 2006.

GRAHAM, Richard. Patronage and Politics in Nineteenth-Century: Brazil. Stanford, EUA: Stanford University Press, 1990. 1 ed.

JANOTTI, Maria de Lourdes Mônaco. O coronelismo: uma política de compromissos. São Paulo: 1992. 3 ed.

KASEKER, Mônica Panis. O desempenho eleitoral de radialistas políticos nas eleições proporcionais de 2002 no Paraná. [dissertação] Mestrado em Sociologia. Curitiba: Universidade Federal do Paraná, 2004.

LEAL, Victor Nunes. Coronelismo, enxada e voto: o município e o regime representativo no Brasil. Rio de Janeiro: Nova Fronteira, 1997. 3 ed.

.O Coronelismo e o coronelismo de cada um. Dados: Revista de Ciências Sociais. Rio de Janeiro: Ed. Campus, v. 23, n. 1, 11-14.

LIMA, Maria Érica de Oliveira. Oligarquia, coronelismo e meios de comunicação. Comunicarte, Campinas - SP, v. 18, n. 24, pp. 103-118, 2001. Disponível em: $<$ http://www.projetoradix.org/artigos/midiadebate/oligarquia_mariaerica.ht $\mathrm{m}>$.

LIMA, Venício Artur de. Existe concentração na mídia brasileira?. In: Conselho de Comunicação Social. (Org.). Concentração da Mídia-debates no Conselho de Comunicação Social. 1a. ed. Brasília: Senado Federal, 2004, v. , pp. 88-114.

.Mídia: crise política e poder no Brasil. 1a.ed. São Paulo: PERSEU ABRAMO, 2006. 1 ed.

.Mídia: Teoria e Política. São Paulo: ED. FUNDAÇÃO PERSEU ABRAMO, 2001. 1 ed.

.Políticas de Comunicações no Brasil: novos e velhos atores. XXI International Congress of the Latin American Studies Association. Chicago, EUA: 1998. Disponível em: <http://168.96.200.17/ar/libros/lasa98/deLima.pdf>.

As bases do novo coronelismo eletrônico. Observatório da Imprensa. Online: n. 341, 08 ago. 2005. Disponível em: < http://observatorio.ultimosegundo.ig.com.br/artigos.asp? $\operatorname{cod}=341 \mathrm{IPBo01}>$.

LUZ, Jane Márcia Lemos. Rádio e TV na Bahia: o partido eletrônico de ACM. [monografia de conclusão do curso de Jornalismo] Faculdade de Comunicação. Salvador: Universidade Federal da Bahia, 1997.

MOURA, A. P. Dos Oligopólios ao Coronelismo Eletrônico: A concentração do poder através das redes de televisão no Brasil. In: $3^{\mathbf{o}}$ Seminário Internacional da Associação Latino-americana dos Pesquisadores da Comunicação, 2005, São Paulo. Anais Alaic, 2005. 
MORLEY, David. Televisión, audiencias y estudios culturales. Buenos Aires: Amorrortu Editores, 1996.

MURDOCK, Graham. Redrawing the Map of the Communication Industries: concentration and ownership in the Era of Privatization. GOLDING, Peter; MURDOCK, Graham (eds.). The Political Economy of the Media. Cheltenham, UK; Brookfield, US: The International Library of Studies in Media and Culture, v. I, 1997. pp. 308-323.

MURDOCK, Graham; GOLDING, Peter. For a Political Economy of Mass Communications. IN: MILIBAND; R. SAVILLE, J. (eds.). The Socialist Register. Londres: Merlin Press, 1974.

PACHECO, Fábio Piva. Mídia e Poder: representações simbólicas do autoritarismo na política. [dissertação] Mestrado em História. Uberlândia: Universidade Federal de Uberlândia, 2001.

PANG, Eul-Soo. Coronelismo e oligarquias, 1889-1943: a Bahia na Primeira República. Rio de Janeiro: Civilização Brasileira, 1979. 1 ed.

MOTTER,Paulino. A Batalha Invisível da Constituinte: Interesses privados versus caráter público da radiodifusão no Brasil. 1994. Dissertação (Mestrado em Ciência Política) - Universidade de Brasília, Conselho Nacional de Desenvolvimento Científico e Tecnológico.

PINTO, Surama Conde Sá. Revisitando "Velhas" Questões: Coronelismo e Clientelismo na Primeira República. In: VIII Encontro Regional de História, 1998, Vassouras - RJ. VIII Encontro Regional de História. Rio de Janeiro : Universidade do Estado do Rio de Janeiro, 1998. v. I. pp. 62-63. Disponível em: < http://www.uff.br/ichf/anpuhrio/Anais/1998/autor/Surama\%20Conde\%20S a\%20Pinto.doc >. Acesso em 13 set. 2006.

RAMOS, Murilo César. [Depoimento] In: SIMON, Pedro (Relator). Rádio \& TV no Brasil: diagnósticos e perspectivas. Relatório da Comissão Especial de Análise da Programação de Rádio e TV, instituída em atendimento ao Requerimento nº 470/95. Brasília: Senado Federal, 1998.

REBOUÇAS, Edgard . Estratégia retórica dos "donos" da mídia como escudo ao controle social. In: XXIX Congresso Brasileiro de Ciênicas da Comunicação, 2006, Brasília. Anais do XXIX Congresso Brasileiro de Ciênicas da Comunicação. São Paulo : Intercom.

REBOUÇAS, Edgard ; FADUL, Ana Maria. Por uma perspectiva metodológica para os estudos dos sistemas e grupos de mídia: o caso do Nordeste brasileiro como referência. In: XXVIII Congresso Brasileiro de Ciências da Comunicação, 2005, Rio de Janeiro. Anais Intercom 2005. São Paulo : Intercom, 2005 .

SANTOS, Reinaldo dos. Da República dos Coronéis à República dos Locutores: homens de mídia e política eleitoral em Ribeirão Preto.. In: V ENLEPICC Encontro Latino de Economia Política da Informação, Comunicação e Cultura., 2005, Salvador - BA. Anais do V Enlepicc. Salvador : UFBA, 2005. v. 1. 
SANTOS, Suzy. Uma Convergência Divergente: a centralidade da TV aberta no setor audiovisual brasileiro. [tese] Doutorado em Comunicação. Salvador: Universidade Federal da Bahia, 2004.

SANTOS, Suzy.; CAPPARELLI, Sérgio. Coronelismo, radiodifusão e voto: a nova face de um velho conceito. In: BRITTOS, Valério Cruz; BOLAÑO, César Ricardo Siqueira (Org.). Rede Globo: 40 anos de poder e hegemonia. São Paulo, 2005, v. 1, pp. 77-101.

SOUSA, João Morais. Discussão em torno do conceito de coronelismo: da propriedade da terra às práticas de manutenção do poder local. Cadernos de Estudos Sociais da Fundação Joaquim Nabuco (Recife/PE), Recife/PE, v. 11, pp. 321-335, 1995. Disponível em: < www.fundaj.gov.br/geral/textos\%20online/sociologia/souza2.pdf> . Acesso em 22 out. 2006.

SOUZA, Regina Luna S. A “cordialidade” na gramática política brasileira e seus efeitos na (in)definição de políticas universais e democráticas de comunicação. Brasília: jul. 2005, mimeo.

STADNIK, Célia. A hipótese do fenômeno do "Coronelismo Eletrônico" e as ligações dos parlamentares federais e governadores com meios de comunicação de massa no Brasil. [monografia] Curso de Jornalismo. Porto Alegre: Faculdade dos Meios de Comunicação Social, PUC-RS, 1991.

VILAÇA, Marcos Vinicios; ALBUQUERQUE, Roberto Cavalcanti. Coronel, Coronéis: apogeu e declínio do coronelismo no nordeste. Rio de Janeiro: Bertrand Brasil, 2003. 4 ed. 